\title{
REDEFINING ETHICS AND CULTURE IN THE VIRTUAL WORLD
}

\author{
Yasraf Amir Piliang $\quad$ |Faculty of Art and Design \\ Institute of Technology Bandung \\ Bandung, Indonesia
}

\begin{abstract}
:
Ethics, and its articulation in moral conducts, is not existed in a vacuum, sterile or fixed human world, but a subject of 'reformulation' or even 'redefinition', as the result of a certain socio-cultural transformation. The development of a global information-digital culture has in a certain intensity affected the perception, understanding and practice of ethics itself as a moral standard. One of the main character of this culture is its 'artificiality', through which human communication and interaction is no longer performed on a 'face-to-face basis, but on a technological mediated one. The consequence is a 'cultural distanciation', in which perception is separated from experience, body is separated from message. Another consequence is the 'transparency' at an ethical level, in which several ethical boundaries are deconstructed: good/bad, proper/ improper. A community ethics is one of today's ethical problem, in which a 'commonality' is no longer constructed based on conventional social bonds, but on more artificial bonds: solitude, rejection, helplessness. Friendship in the digital world is another 'strange' development of moral conduct, in which a great numbers of friends is just an affirmation of one's solitude. As the result, connection - as main pilar in the architecture of our contemporary life- has taken us along a cultural contradiction: it mediates, but at the same time dissociates our cultural experience.
\end{abstract}

Keywords:

ethics - culture $\bullet$ virtuality $\bullet$ communality $\bullet$ connectivity $\bullet$ friendship 
The development of globalisation, information society and cyberculture have affecting a wider social or cultural life, particularly as they are related to moral or ethical dimensions. There has been a radical change or shift on what is ethically understood as good or bad, proper or improper, right or wrong, and moral or immoral. Being the main foundation of what is called a "good life", morality and its ethical basis has in one way or another been deconstructed, the effect of which is the collapse of ethical boundaries or moral limits in the very structure of society itself. This has led us to a kind of chaotic moral situation, immorality or even "hypermorality", that is, a condition of beyond the conventional moral standards.

Moreover, the development of information and communication technology, in particular, has proggresively created an open, transparent and dynamic space, in which everyone can enjoy a relatively more radical freedom, so that he/she can seemingly do anything he/she want to do with a much more unstressed prohibitions, constrains, or regulations as before. As the result, a moral limitation, rule, constraint, or code that traditionally guides or regulates everyday life, can not be completely in effect, since there is no a definite, strong and effective social, cultural or moral mechanism, which can effectively regulate everyday life in the recent changing society and community.

Accordingly, a rethinking or redefinition of ethics and culture in the context of contemporary world is a necessary intellectual duty, as an academic attempt in understanding the recent form or posture of social and cultural life, and how it affects ethical principles and moral conducts. "Rethinking" here is not so much on a completely removal of previous moral standards to be replaced by another as on a creative way to ethically cope with the changing world and new life constellation. In other words, this is a moderate attempt to understand contemporary changing social and cultural life, and to see and find a space for talking about ethical principles and moral conducts in new and challenging ways.

\section{Redefinition of Culture}

Globalisation, in one way or another, is one of the main "boosters' of recent social, political, economic and cultural changes. It has deeply influenced the ethical foundations and moral conducts of our everyday 
life. Yet, globalisation itself is not an unitary concept, since it has several different or even contradictory meanings. On the one hand, globalisation is depicted as tendencies of unification, aliance, interdependence, homogenitation, standardisation, and generalisation, which has created a borderless world, open society, and global culture. ${ }^{2}$ On the other, globalisation is also depicted as tendecies of separatism, autonomy, decentralisation, diversity, plurality, exchange, encounter and hybridity, which can not be unified by a single global principle. ${ }^{3}$

Interconnection and interdependence are two of key concepts in recent social and cultural development of global world, through which one culture meets another in a complex, dynamic and sometime unpredicted way. Deleuze \& Guattari call this tendency as a "rhizome", that is, a kind of "line" in which there are complex relations, interactions, dialogues, exchanges, syntheses, and contestations among different cultures. Here, a culture that is built through the principle of rhizome is the culture that actively connects its semiotics chain, sign system, symbol, meaning, knowledge and code to other cultures, in order to create new and creative relation, sign and knowledge.

The development of an information society or cyberculture is another main "booster" of social, political, economic and cultural change. Cyberspace is an "imagine space", in which everyone can do what he/she wants to do in new unimaginable ways, namely, an artifical way. Being the dominant form of contemporary life, artificial life is highly depended on the role of an advanced information-digital technology, particularly the Internet and other digital media in shaping our social, economic, political, and cultural life. Today, we carry out our everyday life in various unthinkably artifical ways: playing, criticizing, debating, learning, brainstorming, doing business, making love, gossiping, protesting, disputing, creating works, meeting, travelling or even gambling. ${ }^{4}$

Several clues have already been provided, that life has been understood today in a new way as a narrative shaped by advanced information technology, of what is called a "digital narrative". This narrative is a new picture of our form of everyday life, in which our sequences of life has been shaped by various digital technologies: Internet, handphone, Facebook, tele banking, digital money, or tele-shopping. ${ }^{5}$ However strange it may be, this type of narrative has creating various unthinkable or unimaginable 
ways of life: immersion, telepresence, networking, real time interaction, etc. In a much higher scale, it has offerred a kind of new Grand Narrative, that is, a great story of our future life: "human integration" , "borderless citizen", "open society", "virtual community", or "migration of man to a completely artificial life".

To put the above argumen differently, we can understood the space that artifially created through information technology as a new Umwelt, that is, a bounded territory or space, in which one (or a group of people) can define his/her existence in his/her relation to surrounding space or environment, in order to capable of defining his/her own identity and meaning of life. ${ }^{6}$ It is a space, in which one can find security but also apprehension in his/her relation to the external world. ${ }^{7}$ Yet, in the trecent virtual and artifisial world, one lost an important and substantial dimension of life, namely, a concrete spatial dimension, which is naturally manifested through a face-to-face relation. Accordingly, what we find in today artificial world is a kind of Umwelt minus space and territoriality.

As far as form of life is concerned, a life without a concrete space has creating a new way of social interaction and communication, which is now dominantly mediated by the digital technology. The result is a kind of "distanciation" created in our everyday life, in which the artificial worlds of virtual images are separated from our real experiences, of what is so called a "telepresence", as an artificial mode of human tele-interaction, 8 This type of interaction has widely opened a way to a condition of "dissociation" from the world of reality, the effects of which are certain crises in social, cultural and moral order. ${ }^{9}$ One of its significant effect is a kind of social paranoia and moral panics, marked by a restlessness, haste and impatience, ${ }^{10}$ in which there is no space for reflection or meditation of the meaning of life itself. ${ }^{11}$

Another character of our contemporary virtual life is "anonimity", that is, the lost of a true identity of a thing, because everything has no a definite, fixed, stable and coded name, in which everyone can show him/ herself in whatever name. This is because in the virtual world one performs his/herself as a "character" with a particular role or position, as a form of his/her "artificial self". This condition has widely opened a space for everyone to use images, pictures, symbols, characters, or identities, not to uncover "truth", but to distort it. ${ }^{12}$ The result is the creation of a "social 
simulacra", that is, a model of social relation as if it is a real, natural, genuine, or essential social relation, but in fact a false, fake, distorted, reduced or manipulated one. ${ }^{13}$

\section{Beyond Ethics}

From the point of view of morality, the consequencies of recent information society and digital culture can be identified in the emergence of a certain space of "immorality", that is, the space of the free play of moral standards, in order to deconstruct them. This can be seen in social media or the Internet, in which various moral assumptions are reversed and deconstructed, which leaves us in a kind of "moral ruins". ${ }^{14}$ Here, the Internet has became a 'free market' for moral values, in which various moral principles, notions, forms and standards have intersected, collided and mingled one another that makes it more difficult to find any fixed ot durable moral "fondation" or "standard".

To put the argument further, the character of "openness" and "anonim" of the Internet are two characters that open the space for a radical social and cultural actions: erotism, radicalism, extreemism and demonism. In other words, the lack of cultural or moral standard is the main cause of the emergence of the world of "transparency" and the "end of secret", in which everything can be freely opened, created, produced, performed, showed or sold..$^{15}$ Accordingly, there is no longer any cultural or ethical boundary, as a traditional way of filtering various moral threats. Here, "when everything is oversignified and without any partition or filter, meaning itself becomes unattainable. When all values are overexposed.. .then the credibility of of (moral) value is annihilated" . ${ }^{16}$

Based on the above argument, it can be argued furthermore that the transparency created throught information technology has creating a condition of "promiscuity of networks", in which any (social, political, sexual, or cultural) relations can be freely performed. In a "sexual promiscuity", for example, a particular virtual space has been constructing, in which all libidinal cannals are freely opened, and all sexual relations are freely and publicly performed. Here, everyone can watch everyone body through cyberporn on the basis of voyeurism. The "promiscuity of information" has created transparent communication networks, in which all (secret, sexual) information can be accessed by everyone, including children. 
As has by now become very clear, that one of the main effects of the promiscuity is the disappearance of boundary that previously separate the gaze, perception, and knowledge between two different entities, groups or worlds, for instance the boundary between "childhood" and "adulthood". Previously, these two worlds were strictly separated by a kind of moral partition, so that a child can not see, hear, watch or know the world of the adult. However, the power of information technology and virtual culture have deconstructed this partition, so that there is no longer any boundary between the childhood and adulthood.${ }^{17}$ As the result, all children can now enter every "secret" of the adult world, in a kind of "secretless world".

To put the above argument differently, the world constructed through the power of information technology like the Internet, is the world of an "asymetric power relation", as the result of the domination of (digital) media in determining and constructing social and cultural life. This technology capables of creating a new relation of power, namely, "panopticon". This is a system of surveillance using information technology, through which everyone can be secretly watched, observed, inspected, suvervised, stcutinized or spied, in a condition of the invisibility of the watcher. ${ }^{18}$ In other words, information technology capable of creating a kind of a "permanent visibility" by elites who have a seeing power: provider, government, expert or hacker, which has created a serious ethical problem of our contemporary society.

On the other hand, at the level of academic discourse or social movement, various forms of struggle for liberation, emancipation and freedom have been made up in order to create a more symetric world. There is a movement of the liberation of body from any form of domination, because body is regarded as an essential and more concrete property that has to be defended from various repressive power systems, likes the state, media or capitalist power. According to Guattari, body is the site of our identity and the medium to express our desire, pleasure and ecstacy that can not be controlled by any institution or body of power. As remarked by Guattari, "...we have begun with the body, the revolutionary body, as a place where "subversive" energies are produced—and a place where in truth all kinds of cruelties and oppositions have been pepetuated" .19

The recent information, digital, genetic and nano-technology have also capable of creating "body" in its new form and materiality, of what 
is called a "post-human body": robot, cyborg, or clone, which has also a serious ethical problem. This semi-artificial or fully artificial "body" can not be ethically or culturally treated as the same "being" as the realnatural body. This is because differences in their state of mind, thought, soul and consciousness. This leads us to a "posthuman ethics", which is primarily concerned with the standard of "good" or "virtue" for being that beyond the natural body. This is a kind of "ethics" that concerned with ". . .responsibility, in affirmative ethics, comes activity, affectivity, creativity and the solicitation of the unpredictable expressivity of other incarnations of life" 20

\section{The Ethics of Commonality}

In the "communitarian" ethics, conceptions of good, right, virtue, freedom, happiness or "ethics" in general are at every point bound up with our role as members of a cultural community. In the sense that its meaning and significance derived from purposes, values and beliefs of our community. ${ }^{21}$ It is in this community that a principle of "common" is constructed, in which the members of community share their fate based on principles of 'reciprocity' and 'mutual benefit', that can be defined generally through the concept of "common good'. Co-operation is one of ultimate ways in seeking common good, through which common ideals are achieved. ${ }^{22}$

The word "communitas" itself in Latin means thing mingled, unity, brotherhood, alliance, and accosiation. The prefix "cum" means "together with". The root munus means "duty", "office" or " obligation". Here, the concept of community signifies a common property of a particular group of people: land, region, belief, objective, ideology, custom, or value. The connotation of the "common' reminds us to the sociological concept of Gemeinschaft and Gesellschaft. Gemeinschaft_-which is generally translated as a "community" - is characterized by the dominance of close personal ties and kinship relations, which is clearly more related to a smaller group. In contrast, Gesellschaft is more related to what is called a "society", which is characterized by a more impersonal and functional relations.

Community is primarily characterized by the concept of "property", that is, the common belonging of subjects that bonds them together in a group. This property can be regarded as ". . . an attribute, a definition, 
a predicate that qualifies them as belonging to the same totality [insieme], or as a "substance" that is produced by their union". ${ }^{23}$ Community is also characterized by the existence of the "common", which is defined by Spinoza as ". . that which common to all and which is equally in a part and in the whole, does not constitute the essence of any particular". ${ }^{24}$ This kind of common property needs a "common space", namely, a concrete physical space, in which the social relation of the members of community can be performed.

However, the development of the virtual community and cyberculture have created new "community bonds" and "social bonds" as the result of the development of a "network society", which has introducing an entirely different models of bond. Today, the models of Gemeinschaft and Gesellschaft are no longer fully work because of various factors. What we have today is a kind of "community bond" or "social bond' in its new meaning of the word. Here, community or social bond is replaced by ". . . a much more extensive communication than that of a mere social bond and from much more piercing and dispersed segmentation of this same bond, often involving much harsher effects (solitude, rejection, admonition, helplessness)". ${ }^{25}$

To put the above argument differently, the raison de etre of today's community is no longer based on the coventional social bonds: ideology, belief, custom, taboo, kinship, ethnicity, race or nationality, but on more 'artificial' bonds: solitude, rejection, admonition or helplessness. It is in this sense that 'communication' is the main fondation of recent development of community: virtual community, social media group, or digital society. In other words, community is built not so much on the logic of a common ideology or belief as on the logics or sense of "separatedness", "rootlessness", "loss", "emptiness" and "disintegration". As remarked by Esposito, community is " . . nothing other than the limit that separates and joins them ". 26

It can be argued further, that in today virtual community, the essence of communication itself is not a transmission of messages, but precisely an act of communication itself. This is what is called "communicativity", that is, communication built not on the logic of message or meaning, but on the logic of potentiality and fascination of the act of communication itself. ${ }^{27}$ This is what is also called by Baudrillard "the ecstacy of communication", in which communication is performed without any foundation of its value 
or meaning system. As remarked by Baudrillard, “. . .we no longer partake of the drama of alienation, but are in the ecstacy of communication. . .the message has already ceased to exist, it is the medium which imposes itself in its pure circulation". ${ }^{28}$ In a word, we are no longer in an "organic community", with a natural social or community bond, but in an "artificial community", with new sets of artificial bond, moral value and meaning.

\section{The Ethics of Friendship}

'Friend' or 'friendship' is another form of contemporary everyday life that has its new cultural significance and ethical meaning. What has been taken place is a philosophical transformation of the concept of 'friend' or 'frienship' itself, as the result of the development of an advanced informaton-digital society, in which social relation has been built based on a model of virtual network, and where friendship is the effect of these network. In this virtual network, the concept of friend or friendship has been whipped out from a face-to-face social relation, and has been artificially built in a virtual space, in which concepts of proximity, closeness, and community are part and parcel of its new logic.

In this connection, Aristotele distinguished three kinds of friendship (philia) based on its motive: utility, pleasure and goodness. ${ }^{29}$ Utility is the motive of friendship when we assume certain values of goodness or benefit that can be obtained from someone: energy, thought, skill, intelligence, or popularity. Pleasure is the motive of friendship when we assume that we can get satisfaction from someone. Virtue is the motive of friendship when we see the good itself from someone's character or behaviour. In this context, perfect friendship is a friendship among good people, who all have virtue, desire good things, and have goodness in their own self. ${ }^{30}$ This perfect frienship can only be achieved in a relative small number of friend, never in a great number.

The development of information society and cyberspace have created a new form of friendship, namely "technological friendship": Facebook, Twitter, Line, WhatsUp. In this new kind of space, we have new ethical 'terms': on/off, invite friend, delete friend, find friends, close friends, or suggest friend, all of them are indefinite cultural categories. Here, to find friends is not based on a face-to-face relation but on a virtual encounter that is artificial in its nature. In this new social relation, what we have is 
a kind of "virtual intimacy", that is, an intimacy without closeness, or "closeness in the distance", in which one can be 'close' or 'intimate' to someone else, entirely without any face-to-face encounter. Here, a genuine friendship characterized by closeness (in space) has lost its meaning, because friendship today is strangely characterized by "dissociation", where closeness is totally whiped out from experience in the real world. ${ }^{31}$

Furthermore, Aristotle tried to relate the quality of frienship to a number, where the fewer the number the better the quality of friendship, and vice versa. This is why, according to Aristotle, we do not have to find friends as many as possible, but as many that is necessary to build a mutual good community life. This is because ". . . it would seem to be impossible to be a devoted friend of a number of people. So too it is impossible to be the devoted friend of more than a few people". ${ }^{32}$ However, the development of recent social media has strangely created a new artificial model of friend and frienship. In the Facebook for example, friendship is essentially not for utility, pleasure or goodness, but for "network-fornetwork-shake", that is, a friendship for demonstrating the "great number" and popularity: the bigger the number the more popular someone in the network. This is absolutely an opposite of Aristotle's picture of a perfect friendship that can only be acieved in a relatively fewer number.

Moreover, friendship, according to Nietzsche, is something that has no clear boundaries, because its complexity and plurality. ${ }^{33}$ Derrida, for example, portrays friendship as a "grief": damage, fault, prejudice, injustice, injury, resentment, grievance, a call for revenge. ${ }^{34}$ But, however unclear it may be, one definite thing about friendship is that, there is only friendship if there is an horizon of expectation built by a group of people. Hence, the enemy of friendship is a 'loneliness', 'solitude', 'deserted', or 'isolation'. Yet, ironically, what we find in the community of friendship in Facebook, Twitter, Line, WhatsApp, or BB Group are these loneliness, solitude, deserted and isolation. This is because the people who seek friendship in these various media are lonely men, who are called by Derrida as the 'community of those without community'. They asemble together just to affirm their loneliness and solitude. ${ }^{35}$

It is the fact that one accumulates as many friend as possible in Facebook or Twitter. Yet, these great numbers of friend is just a negation of the basic essense of friedship itself: closeness, intimacy, familiarity, 
solidarity, and togetherness. One finds and interacts with his/her abudance of friends just in his/her loneliness: sitting in a lonely room in front of an isolated laptop. Here, Facebook is a perfect example of Derrida's notion of the 'community of those without community', who has similarity each other in term of loneliness, solitude, deserted and isolation. These are the people who build an architecture of loneliness through friends just to affrim their solitude. The greater the number of friends the deeper the solitude that incarcerate them in the world of isolation. This is to affirm Nietzchean notion about friendship: "Friend, there is no friend!"

\section{The Meaning of Connectedness}

Friend or friendship is one of phenomena in today's digital world, which is performed in a kind of placeless or spaceless relationship of human being. Instead of performed in a "face-to-face" relationship in a real space, friendship in today's Internet world, is performed in a technological-mediated world of a wire connection. 'Connection' is a new essence of human relation, through which almost all human activities are permormed in a new artificial-virtual way. Connectivity is a mean of communication or interaction mediated through technology, particularly information-digital technology. The characteristic of connectivity, in this sense, is "mediatedness", that is, the role of technology in linking two or more persons.

A connection, in term of family tie, kinship, or association, is esentially associated with a condition of being psychologically, socially or geographically "close" and "intimate". In other words, it is a total closeness or intimacy. But, in a technological-mediated connection, the contents, objects, and place, where the communication or interaction is performed are all 'artificial'. In this artificial model, a human performace is mediated - but at the same time 'separated' — by technology. The result is the separatedness of body and message, in which "... matterless signs travel through space and time, waves spread out, and bodiless communication becomes possible. This realm of immaterial signs has settled into telematic civilization". 36

Here, a spacelessness, placelessness, bodilessness and immateriality can be seen as the main construction of our recent architecture of human communication or interaction. This is because communication and interaction are mediated through artificial images, that makes it impossible 
to incorporate "perception" and "experience" as a total human capacity. Here, human experience is essentially "immaterialised", because ". . vision is becoming separated from experience, and the world is fast assuming a derealised quality. The proliferating system of new vision and image technologies is now instituting what can only be regarded as structural and generalised condition of dissociation from the world" 37

'Dissociation' is a condition, in which perception is separated from the real world. In a conventional meaning of Gemeinschaft and Gesellschaft, community or society is tied not only by a common property, belief or ideal, but also by common place in the physical meaning of the word. In this place people have a strong sense of place-the room or village or city - where their interaction occur. In a virtual communities people have a different mental model of 'sense of place'that requires an individual act of imagination or "imagined community". Here, space, place, body, object, or environment are things that has to be imagined, because they do not have a real or concrete physical existence. ${ }^{38}$

In this kind of 'artificial reality', it is impossible to relate an object, body or place to the concept of 'unique' or 'originality' of thing. This because the concept of 'uniqueness' connotes the singleness of thing, that is to say, the existence of thing in a particular space or place, not in other spaces or places, sui generis. For example, an unique big flower in the forest of Sumatra, or an original Affandi's painting "Cock Fighting". In contrast, it is not make sense to talk about the uniqueness of ones profile image in the Facebook, or the originality of certain image in the Internet. This is because, the profile and images are not existed in a concrete-physical place or environment.

'Conversation' is another dimension of our information-digital world that has been experienced and understood in a new artificial-contradictive way. A conversation in the real-physical world is basically taken place in a 'face-to-face' model, in which the participants share the concrete-physical world of environment. In contrast, conversation in our information-digital world is mediated dominantly through 'screen'-particularly electronicdigital screen — as a primary element of the contemporary everyday life. Here, almost no contemporary human activity that does not practically or technologically depend on the existence of screen: economy, politic, education, industry, entertainment, religion or even criminality. 
Being a dominant element of contemporary form of life, screen is a medium, which represents the world through various images: mental, verbal, visual, tactical. Yet, screen is not merely a medium of representation, but it now becomes an inseparable part of the construction of human existential consciousness, namely, a 'being-in-the-world' of Dasein. Consciousness that was previously constructed in the basis of a direct experiences of living with other human being, natural environment, and man-made-things, today becomes an experience mediated by a screen. In front of of a screen, the structure of consciousness is constructed on the basis of an experience of coping with artificial images of our artificial world.

To put the above argument differently, conversation mediated by screen is the "conversation in distance", in which the "place' where conversation is performed is a cognitive and social one, but not geogpraphical. It is in this sense, that closeness in space is kind of "closeness in distance", that is to say, the closeness without spatial intimacy, a contradictive intimacy. Hence, 'contradiction' is another character of our recent informationdigital world, in which one does thing through a means that contradicts its own end: to get a close relationship through a distance, to build a closed friendship without intimacy - a contradictio in terminis.

\section{Bibliography}

Agamben, Giorgio. The Coming Community. Minneapolis: University of Minnesota Press, 2007.

Aristoteles. Nicomachean Ethics. Cambridge: Cambridge University Press, 2000.

Baudrillard, Jean. In the Shadow of the Silent Majorities, or, the End of the Social, and Other Essays. New York: Semiotext(e), 1983.

- Baudrillard Live: Selected Interviews. London, New York:

Routledge, 1993.

. Revenge of the Crystal: Selected Writings on the Modern Object and Its Destiny, 1968-1983. London: Pluto Press, 1990.

. The Ecstasy of Communication, New York: Semiotext(e), 1987. 
Coyne, Richard. Technoromanticism: Digital Narrative, Holism, and the Romance of the Real. Massachusetts: The MIT Press, 1999.

deBeistegui, Michel. Thinking with Heidegger: Displacements. Bloomington: Indiana University Press, 2003.

Derrida, Jacques. The Politics of Friendship. London: Verso, 2005.

deSpinoza, Benedict. The Ethics. New York: Dover Publications Inc., 1955.

Druckery, Timothy. Electronic Culture: Technology and Visual Representation. Aperture, 1996.

Esposito, Roberto. Communitas: The Origin and Destiny of Community. Stanford: Stanford University Press, 2010.

Foucault, Michel \& Sheridan, Alan. Discipline and Punish: the Birth of the Prison. London: Penguin Books, 1986.

Gleick, James. Faster: The Acceleration of Just Everything. New York: Pantheon Book, 1999.

Guattari, Félix \& Lotringer, Sylvère. Chaosophy: Soft-Subversion. New York, N. Y.: Semiotext(e), 1996.

Kamper, Dietmar \& Wulf, Christoph. Looking Back on the End of the World. New York: Semiotext(e), 1989.

Kofman, Eleonore \& Youngs, Gillian. Globalization: Theory and Practice. London: Pinter, 1996.

MacCormack, Patricia. Posthuman Ethics: Embodiment and Cultural Theory. Farnham: Ashgate Pub., 2012.

MacIntyre, Alasdair. After Virtue A Study in Moral Theory. London: Duckwoth, 1999.

Nancy, Jean-Luc. The Inoperative Community. Minneapolis: University of Minnesota Press, 1991.

Nietzsche, Friedrich Wilhelm. Human All Too Human. Cambridge: Cambridge University Press, 2007.

Price, A.W. Love and Friendship in Plato and Aristotle. Oxford: Oxford University Press, 2004.

Rheingold, Howard. The Virtual Community: Finding Connection in a Computerized World. London: Secker \& Warburg , 1994. . Virtual Reality. London: Mandarin, 1991.

Robins, Kevin. Into the Image: Culture and Politics in the Field of Vision. London: Routledge, 1996.

Sandel, Michel J. Liberalism and the Limits of Justice. Cambridge: Cambridge 
University Press, 1984.

Scott, Alan. The Limits of Globalization: Cases and Arguments. London: Routledge, 1997.

Virilio, Paul \& Beitchman, Philip. The Aesthetics of Disappearance. New York, N.Y.: Semiotext(e), 1991.

Virilio, Paul \& Rose, Julie. Open Sky. London, New York: Verso, 1999.

Young, Jock. The Exclusive Society, Social Exclusion, Crime and Difference in Late Modernity. London: Sage Publication, 1999.

\section{Endnotes:}

1 Professor at Faculty of Art and Design, Institute of Technology Bandung, Indonesia.

2 V. Aspike Peterson, "Remapping in the Context of Globalization", Globalization: Theory and Practice, ed. Eleonore Kofman \& Gillian Youngs (Pinter, 1996) 12.

3 Ahmed Gurnah, "Elvis in Zanzibar", The Limits of Globalization: Cases and Arguments, ed. Alan Scott (London: Routledge, 1997) 120.

4 Howard Rheingol is one of proponents of the development information-digital culture and virtual life, who propose a positive, constructive and optimistic vision of the role of information-digital technology in shaping our future everyday life. Here, technology is not only regarded as an extension of human body, but also human brain, so that we can do everything that previously can not be performed by human personal capacity: thinking, copying, repeating, drawing, calculating, multiplying, spying. See Howard Rheingold, The Virtual Community London: Secker \& Warburg, 1994) 3.

5 Richard Coyne, Technoromanticism: Digital Narrative, Holism, and the Romance of the Real (Massachusetts: The MIT Press, 1999) 7.

6 Michel deBeistegui, Thinking with Heidegger: Displacements (Bloomington: Indiana University Press, 2003) 143.

7 Jock Young, The Exclusive Society, Social Exclusion, Crime and Difference in Late Modernity (London: Sage Publication, 1999) 71.

8 Paul Virilio, Open Sky (London: Verso, 1999) 25.

9 Kevin Robins, Into the Image: Culture and Politics in the Field of Vision (London: Routledge, 1996) 13.

10 James Gleick, Faster: The Acceleration of Just Everything (New York: Pantheon Book, 1999) 9.

11 Paul Virilio, The Aesthetics of Disappearance (New York: Semiotext(e), 1991) 22.

12 Sherry Turkle, "Constructions and Reconstructions of the Self in Virtual Reality", Electronic Culture: Technology and V isual Representation, ed. Timothy Druckery, (Ontario and London: Aperture, 1996) 354-365.

13 Jean Baudrillard, In the Shadow of the Silent Majorities (New York: Semiotext(e), 1983) 66.

14 Jean Baudrillard, Baudrillard Live (London: Routledge, 1993) 95.

15 Jean Baudrillard, Revenge of the Crystal: Selected Writings on the Modern Object and Its Destiny, 1968-1983 (London: Pluto Press, 1990) 163. 
16 Ibid. 190.

17 Dieter Lenzen, "Disappearing Adulthood', Looking Back on the End of the World, ed. Dietmar Kamper \& Christoph Wulf (New York: Semiotext(e), 1989) 64-78.

18 Michel Foucault, Discipline and Punish (New York: Penguin Books, 1986) 200.

19 Felix Guattari, Soft-Subversion (New York: Semiotext(e), 1996) 35.

20 Petricia MacCormack, Posthuman Ethics: Embodiment and Cultural Theory (Surrey: Ashgate, 2012)13.

21 Alasdair MacIntyre, After V irtue (London: Duckwoth, 1999) 232.

22 Michel J. Sandel, Liberalism and the Limits of Justice (Cambridge: Cambridge University Press, 1984) 133-154.

23 Roberto Esposito, Communitas: The Origin and Destiny of Community (Stanford: Stanford University Press, 2010) 2.

24 Benedict deSpinoza, The Ethics (New York: Dover Publications Inc., 1955) Part II, Proposition 37.

25 Jean Luc Nancy, The Inoperative Community (Minneapolis: University of Minnesota Press, 1991) 11.

26 Esposito, op. cit. 149.

27 Giorgio Agamben, The Coming Community (Minneapolis: University of Minnesota Press, 2007) 81.

28 Jean Baudrillard, The Ecstacy of Communication (New York: Semiotext(e), 1987) 23.

29 A.W. Price, Love and Friendship in Plato and Aristotle (Oxford: Oxford University Press, 2004) 104.

30 Aristoteles, Nicomachean Ethics (Cambridge: Cambridge University Press, 2000) 147.

31 Robins, op. cit. 13.

32 Aristoteles, op. cit. 318.

33 F. Nietzsche, Human All Too Human (Cambridge: Cambridge University Press, 2007) 149.

34 Jacques Derrida, The Politics of Friendship (London: Verso, 2005) ix.

35 Ibid., 37.

36 Peter Weiber, "The World as Interface; Toward the Construction of ContextControlled Event-World", dalam Timothy Druckery (Ed.), Electronic Culture: Technology and Visual Representation (Aperture, 1996) 339.

37 Robins, op. cit. 13.

38 Howard Rheingold, The Virtual Community: Finding Connection in a Computerized World (London: Secker \& Warburg, 1994) 63. 